\title{
ALLERGIC RHINITS AND ITS IMPACT ON ASTHMA - ARIA. CONTROL AND PREVENTION OF RESPIRATORY ALLERGIES IN PHARMACY PRACTICE
}

\author{
Anna Todorova ${ }^{1}$, Antoaneta Tsvetkova ${ }^{2}$, Dimitar Dimitrov ${ }^{1}$ \\ ${ }^{1}$ Department of Pharmaceutical Sciences, Faculty of Pharmacy, \\ Medical University of Varna \\ ${ }^{2}$ Assistant Pharmacists Education and Research Center, Medical College of Varna
}

\begin{abstract}
Epidemiological studies on respiratory allergies have shown that allergic rhinitis (AR) and bronchial asthma (BA) often coexist in the same patient. The premise "one respiratory system, one disease" marks a change in diagnostic and therapeutic treatment of respiratory allergies. Allergic Rhinits and Its Impact on AsthmaARIA Initiative at WHO aims to spread, educate and implement evidence-based management of allergic rhinitis as a risk factor for development of asthma worldwide. This study reviews current concepts and trends in the management of respiratory allergies in compliance with the recommendations of ARIA.
\end{abstract}

Keywords: allergic rhinitis, bronchial asthma, ARIA, management

\section{INTRODUCTION}

Atopic diseases, being relatively rare until a few decades ago, are a serious health, economic and social problem. According to World Health Organization (WHO) allergic diseases affect more than $40 \%$ of the population in developed countries (15). About $10 \%$ of children and $25 \%$ of adults suffer from allergic diseases. Publication data show that prevalence of AR in children is between 20 to $30 \%$ (4). The percentage of pediatric patients with asthma grows rapidly, in some of the developed countries reaching up to $15 \%$, and in some regions, social strata and ethnic groups exceeding $20 \%$ (11).

Address for correspondence:

Anna Todorova

Department of Pharmaceutical Sciences,

Faculty of Pharmacy, Medical University of Varna

84 Tsar Osvoboditel Blvd,

9000 Varna, Bulgaria

e-mail:annitodorova@abv.bg

Received: November 14, 2014

Accepted: December 1, 2014
Studies show that $87 \%$ of children with asthma suffer from allergic rhinitis, and patients with allergic rhinitis are at three times higher risk than the general population of developing asthma (18). The concept of a continuous airway views allergic rhinitis and asthma as a manifestation of the same pathological process - an allergic inflammation (2). Undiagnosed and untreated, AR increases the risk of development of asthma by about three times, adversely affects asthma attacks and increases the likelihood of hospitalization by $50 \%$. Proper treatment and control of AR can improve BA and reduce the risk of its development (16). Through ARIA (Allergic Rhinits and Its Impact on Asthma) Initiative, WHO educates and provides guidelines for treatment of AR to prevent its progression to asthma.

\section{SEVERITY ASSESSMENT OF ALLERGIC RHINITIS}

ARIA introduces a new classification, dividing AR into "intermittent" and "persistent" and replacing the previously used division of rhinitis into seasonal and perennial. Intermittent $A R$ is defined by symptoms that occur for up to 4 days per week, not 
Anna Todorova, Antoaneta Tsvetkova, Dimitar Dimitrov

more than 4 consecutive weeks, whereas persistent AR lasts for more than 4 days per week and for more than 4 consecutive weeks. Based on severity of symptoms and the degree to which they affect the patient's quality of life, allergic rhinitis is classified as mild or moderate-severe (5) (Fig.1).

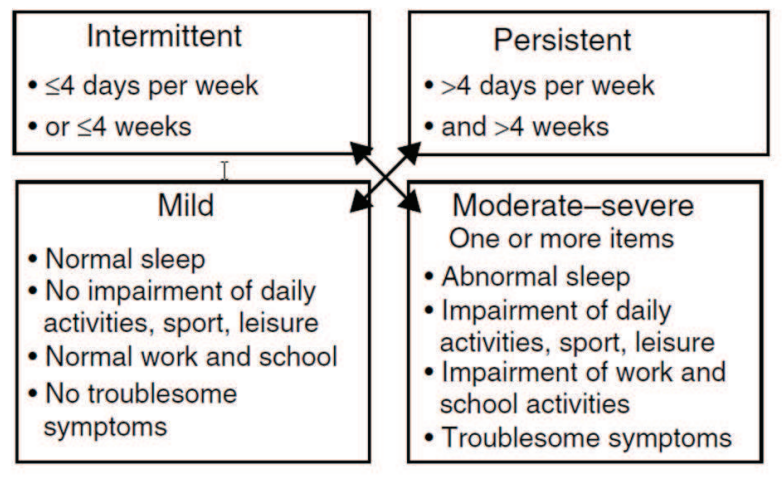

Fig. 1. Classification of allergic rhinitis according to ARIA (2)

ARIA classification reflects the condition of the patient and serves as basis for determination of AR treatment and evaluation of its control (16).

A study of over 3000 AR patients consulting general practitioners demonstrated that $93 \%$ of the patients had a diagnosis of moderate-to-severe rhinitis and the remaining 7\% - a diagnosis of mild rhinitis (7).

\section{TREATMENT OF AR ACCORDING TO ARIA} GUIDELINES

Behavior in allergic rhinitis based on ARIA and WHO Guidelines includes: avoidance of contact with the specific allergen (allergens) or with precipitating factors, pharmacological therapy, immunotherapy, patient education (20) (Fig. 2).

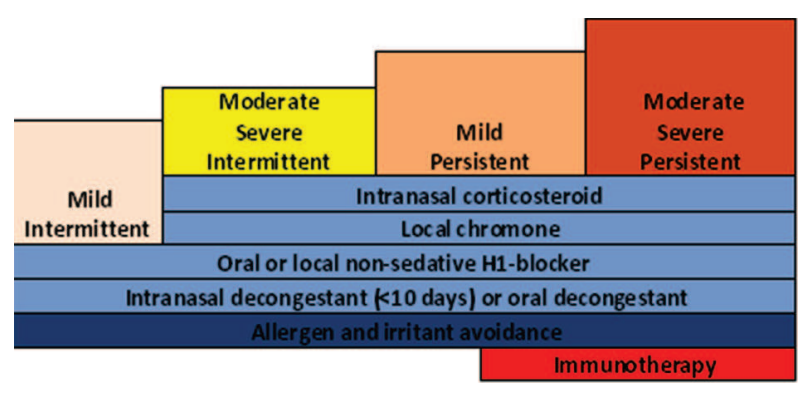

Fig. 2. ARIA Guidelines for the Treatment of Allergic Rhinitis (20)
Allergen removal is recommended whenever possible. In recent years, nasal irrigations with a saline solution are more and more often used. They provide mechanical removal of the allergen and moisturizing and have a decongestant effect.

\section{PHARMACOTHERAPY}

A wide spectrum of medications is available for the treatment of allergic rhinitis. Therapy can be tailored to specific clinical symptoms, treatment regimen can involve a single medication or multiple medications, depending on the severity of symptoms. Combining medications of different classes is effective, as they influence inflammatory mechanisms differently. Antihistamines and intranasal corticosteroids are the treatment of choice in patients with moderate to severe symptoms. Once symptoms are controlled, the number of medications can be reduced to a single agent (5). The agents used to treat allergic rhinitis include antihistamines, decongestants, corticosteroids, mast cell stabilizers, anticholinergic agents, leukotriene receptor antagonists and immunotherapy (20).

\section{Antihistamines}

Although antihistamines are effective in the treatment of allergic rhinitis, the use of first generation antihistamines (Chlorpheniramine, Clemastine, Diphenhydramine, Ketotifen) has been limited by adverse effects due to lack of selectivity for the $\mathrm{H} 1$ receptor and propensity to cross the blood-brain barrier (14). Second generation antihistamines (Cetirizine, Loratadine, Fexofenadine, Levocetirizine, Desloratadine) are developed to increase the selectivity for the $\mathrm{H} 1$ receptor and eliminate anticholinergic and sedative side effects inherent to first generation agents. According to ARIA, oral or local nonsedating $\mathrm{H} 1$ blockers are recommended as first-line therapy in all forms of allergic rhinitis regardless of clinical symptom severity (20). According to studies, long-term antihistamine treatment of patients with persistent AR significantly reduces the incidence of asthma episodes and the need of administration of asthma attack medications (19).

\section{Decongestants}

Decongestants come in oral and intranasal form. Long-term use of oral decongestants (Ephedrine, Phenylephrine, Phenylpropanolamine, Pseudoephedrine) is undesirable because of their side effects: 
nervousness, insomnia, irritability, headache, increased blood pressure, heart palpitations and tachycardia. Nasal decongestants (Epinephrine, Naphazoline, Oxymethazoline, Xylomethazoline) provide faster and more powerful congestion relief compared to oral. Their long-term use is not recommended because of the risk of causing irreversible damage to nasal mucous membranes (2).

\section{Intranasal Corticosteroids}

Because of the broad anti-inflammatory activity of nasal corticosteroids (Fluticasone, Beclomethasone, Budesonide, Mometasone, Ciclesonide), they are highly effective in the treatment of allergic rhinitis. They are recommended as first-line therapy for intermittent moderate to severe allergic rhinosinusitis and persistent allergic rhinitis (2). Compared with antihistamines and cromolyns, intranasal corticosteroids have a powerful effect on sneezing and nasal congestion. Maximum effect is achieved after prolonged use. When given before the allergy season, intranasal corticosteroids can prevent symptoms or reduce their severity. Nasal corticosteroids are considered safe. The most common adverse effect is epistaxis, which can occur in up to $10 \%$ of patients (17).

\section{Mast Cell Stabilizers (Chromones)}

Although chromones (Sodium cromoglycate, Nedocromil) help control the symptoms of allergic rhinitis and their safety profile is excellent, the use of Sodium cromoglycate or nedocromyl is limited. Their therapeutic effect is less pronounced compared to other medications and in severe symptoms treatment with them is not effective enough. Chromones require dosing four times daily, making patient compliance difficult. Chromones are more effective if given before exposure to the allergen, for example, with preseasonal treatment (2).

Leukotriene Receptor Antagonists (Montelukast, Pranlukast, Zafirlukast)

These medications were used initially in the treatment of bronchial asthma, but they also have demonstrated efficacy in treating allergic rhinitis. Their efficacy is similar or slightly less than that of antihistamines and significantly less than that of intranasal corticosteroids (13). The main indications for use are in patients who are unable to use intranasal corticosteroids or antihistamines or as an additional medication for patients whose allergic rhini- tis is not sufficiently controlled with intranasal corticosteroids. In many cases, in patients with mild to moderate-severe persistent asthma and allergic rhinitis, they are preferred as monotherapy (8).

\section{ALLERGEN-SPECIFIC IMMUNOTHERAPY}

Allergen specific immunotherapy interferes with the basic mechanisms of the allergy and alters the natural course of allergic diseases, resulting in symptomatic relief and offering the patient a longlasting and preventive effect. These are observed using both subcutaneous and sublingual routes. Subcutaneous immunotherapy was shown to reduce the onset of new sensitisations as well as the development of asthma in patients with allergic rhinitis $(10,15)$. Immunotherapy is now recognised as complementary to the pharmacological treatment for respiratory allergy. It is suggested that immunotherapy should be initiated early in the course of the disease, when irreversible damages are not yet established and when it is still possible to modify the progression of the disease. However, it is usual to start this treatment after the age of 5 .

\section{PATIENT EDUCATION}

It has been found that low public awareness of allergies as serious chronic disease is a major issue. Patients suffering from respiratory allergies are not fully aware of the importance of the management of allergies and the implications accompanying their progression. Patients, especially those with mild allergies tend to adapt to their symptoms or resort to self-medication without consulting the doctors (3). According to data published, in Europe only $45 \%$ of patients with allergic rhinitis seek medical advice or treatment of their disease (6). Patients should be educated to avoid exposure to allergens and other precipitating factors, for possible side effects of therapy (medications and immunotherapy), allergic rhinitis complications and its impact on asthma.

PHARMACIST'S ROLE AS A CONSULTANT TO HELP PATIENTS WITH RESPIRATORY ALLERGIES

The key to effective treatment and control of respiratory allergies is collaboration between patients, pharmacists and health care professionals. Allergy is a disease that should be monitored even in the absence of exacerbations. Pharmaceutical care includes consultations, prevention, monitoring and evalu- 
ation of treatment (9). In accordance with ARIA guidelines (1) pharmacists play role in:

* Recognizing allergic rhinitis and distinguishing it from other conditions, including infections

* Assessing AR severity

* Selling OTC medications and advising patients with intermittent and mild persistent AR where it is possible to achieve control

* Referring patients with uncontrolled and persistent severe AR to a physician

Fig. 3 shows the pharmacist's approach in advising patients with allergic rhinitis according to ARIA guidelines.

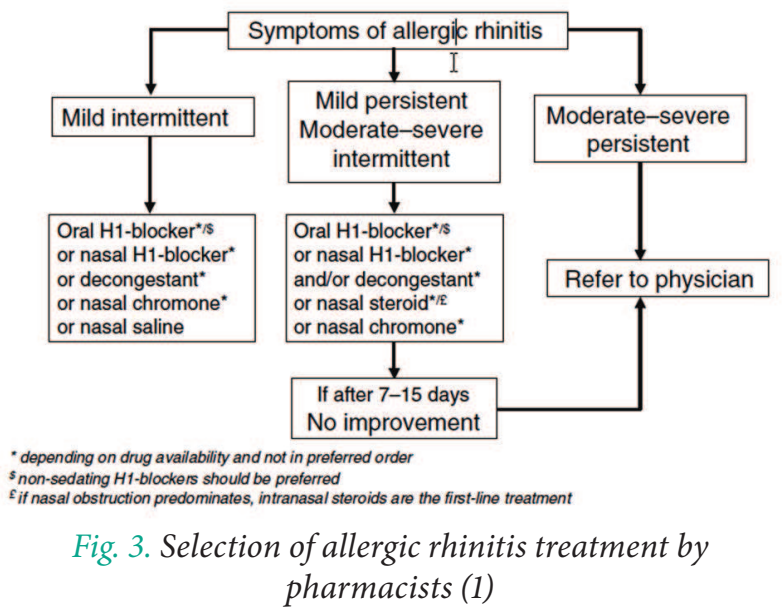

To prevent allergic rhinitis exacerbations, pharmacists should render services that ensure the proper use of medications, the optimal therapeutic outcome and the prevention of adverse drug reactions. This should be implemented through the collaborative efforts of pharmacists, physicians and patients.

As a reliable source of medical information and advice, pharmacists play a crucial role in the selfmedication of patients with intermittent and persistent allergic rhinitis, whose symptoms can be effectively controlled. Antihistamines are often used indiscriminately and without the supervision of a physician because of their OTC drug status. This underscores the importance of patient counselling provided by pharmacists.

Moreover, pharmacists should be able to recognize the different types of allergic rhinitis in order to recommend an appropriate treatment with OTC drugs. Patients with uncontrolled severe persistent allergic rhinitis should be referred to a physician.

According to ARIA in the Pharmacy, patients with allergic rhinitis should be questioned and monitored for symptoms of concomitant asthma. If undiagnosed or uncontrolled BA is suspected, they should be referred to a specialist physician (1).

\section{DISCUSSIONS}

Regardless of the accumulation of knowledge and clinical experience, allergic rhinitis remains a hypo-diagnosed disease. Persistent AR is often concealed from acute and chronic rhinosinusitis, otitis, bronchial asthma.

Timely treatment of allergic rhinitis should be deemed an important element of the treatment and control of bronchial asthma and an essential part of asthma prevention.

Being the most accessible source of health information, pharmacists have to meet the constantly increasing requirements of modern healthcare systems.

The aim of pharmacy practice is to contribute to public health improvement by providing patient counselling and advice on disease prevention, pharmacovigilance, health monitoring and an adequate disease therapy. Pharmacists' skills and competence in the contemporary society can ensure optimal drug use, higher efficacy of pharmacotherapy and a reduction in healthcare systems' costs.

\section{CONCLUSION}

An essential part of pharmacists' responsibilities is the implementation of effective pharmaceutical care. The introduction of additional training programs and the constant updating of pharmacists' skills and competence are essential for the active participation of healthcare professionals in the prevention and treatment of respiratory allergies.

Early diagnosis and adequate management in cooperation with patients, medical and health professionals can improve the quality of life of the patients and influence the frequency and severity of comorbid pathology. 
Allergic rhinits and its impact on asthma - aria. Control and prevention of respiratory allergies in pharmacy practice

\section{REFERENCES}

1. ARIA Pocket Guide for Pharmacists. In Edition 2003.

2. Bousquet J, Van Cauwenberge P, Khaltaev N. Allergic rhinitis and its impact on asthma, J Allergy Clin Immunol, 2001;108(5 Suppl):147-334.

3. Bousquet J, Van Cauwenberge P, Khaltaev N. Allergic rhinitis and its impact on asthma (ARIA)- Executive summary. Allergy, 2003;57:841-855.

4. Bjorksten B, Clayton T, Ellwood P, Stewart A, Strachan D. Worldwide timetrends for symptoms of rhinitis and conjunctivitis: Phase III of the International Study of Asthma and Allergies in Childhood. Pediatr. Allergy Immunol., 2008;19:110-124.

5. Brozek JL, Bousquet J, Baena-Cagnani CE et al. Allergic Rhinitis and its Impact on Asthma (ARIA) guidelines: 2010 revision. J Allergy ClinImmunol, 2010;126,466-476.

6. Canonica GW, Bousquet J, Mullol J et al. A survey of the burden of allergic rhinitis in Europe. Allergy, 2007;62(Suppl 85), 17-25.

7. Ciprandi G, Cirillo I, Vizzaccaro A, Tosca M, Passalacqua $G$, Pallestrini E et al. Seasonal and perennial allergic rhinitis: is this classification adherent to real life? Allergy, 2005;60:882-887.

8. Currie G, Devereux G, Lee D et al. Recent developments in asthma management. British Medical Journal, 2005;330:585-589.

9. Dessing RP. Ethics applied to pharmacy practice. Pharm World Sci, 2000;22:10-16.

10. Di-Rienzo V, Marcucci F, Puccinelli P, et al. Long-Lastingeffect of sublingual immunotherapy in children with asthma due to house dust mite: a 10-year prospective study. ClinExpAllergy, 2003;33:206-210.

11. Ellwood P, Asher MI, Beasley R, Clayton TO, Stewart AW, the ISAAC Steering Committee. The international study of asthma and allergies in childhood (ISAAC): Phase Three rationale and methods. Int J Tuberc Lung Dis, 2005;9(1):10-6.

12. Marshal GD: Internal and external environmental influences in allergic diseases. J Am Ostheopath Assoc 2004;104:51-56.

13. Meltzer E, Malmstrom K, Lu S, et al. Concomitant montelukast and loratadine as treatment for seasonal allergic rhinitis: placebo-controlled clinical trial. J Allergy Clin Immunol, 2000;105:917-922.
14. Milgrom $\mathrm{H}$, Bender $\mathrm{B}$, Wamboldt F. Of injuries and antihistamines and dosing. Ann Allergy Asthma Immunol 2002;89:221-223.

15. Moller C, Dreborg S, Ferdousi HA, et al. Pollen immunotherapy reduces the development of asthma in children with seasonal rhinoconjunctivitis (thePATstudy). J Allergy Clin Immunol, 2002;109:251-256.

16. Pawankar R, Canonica G, Holgate S, Lockey R. WAO White Book on Allergy 2011-2012. In Edition Milwakee, Wisconsin, USA: WAO 2011.

17. Plaut $M$ and Valentine MD. Clinical practice: allergic rhinitis. N. Engl. J. Med., 2005;353:1934-1944.

18. Thomas M, Kocevar VS, Zhang Q et al: Asthma related healthcare resourse use among asthmatic children with and without concomitant allergic rhinitis. Pediatrics, 2005;115: 129-134.

19. www.eaaci.net/site/homepage.php - EAACI - European Academy of Allergology and Clinical Immunology.

20. www.whiar.com - Allergic Rhinits and Its Impact on Asthma (ARIA). 